\title{
Colorectal cancer survival: prevalence of psychosocial distress and unmet supportive care needs
}

\author{
Yolanda Andreu ${ }^{1} \cdot$ Paula Martinez ${ }^{2}$ (1) $\cdot$ Ana Soto-Rubio ${ }^{1} \cdot$ Silvia Fernández $^{3,4} \cdot$ Carles Bosch $^{4} \cdot$ Andrés Cervantes $^{5}$
}

Received: 23 March 2021 / Accepted: 20 August 2021 / Published online: 16 September 2021

(c) The Author(s), under exclusive licence to Springer-Verlag GmbH Germany, part of Springer Nature 2021

\begin{abstract}
Purpose The aim of this study was to determine the prevalence of distress and unmet supportive care needs in post-treatment colorectal cancer (CRC) survivors. Also, to explore the association between both variables and to identify potential associated sociodemographic and cancer-related risk factors.

Methods A cross-sectional study of 200 CRC survivors who at least 1 month before had completed the primary treatment for CRC was conducted. The Brief Symptom Inventory-18 (BSI-18) and the Spanish version of Cancer Survivors' Unmet Needs (S-CaSUN) were used.

Results One in five CRC survivors showed clinical distress and $86 \%$ expressed at least one unmet need. Distress was positively associated with the prevalence of needs in all domains. All comprehensive care and information needs were expressed by at least $20 \%$ of survivors and some by more than $50 \%$. Other needs also mentioned by $20 \%$ of survivors were financial support, ongoing case manager, and concerns about cancer recurrence. The risk factors associated were lower socioeconomic status, younger age, and a primary treatment that includes more than surgery.

Conclusions The findings highlight the relevance of extending psychosocial care beyond the CRC primary medical treatment. A person-centered approach that addresses informational, emotional, social, and physical needs can increase satisfaction with care and also prevent psychological morbidity in CRC survivors.
\end{abstract}

Keywords CRC survivorship · Emotional distress · Supportive care needs · Cancer Survivors Unmet Needs measure · Psycho-oncology

\section{Introduction}

The steady increase in cancer survival imposes a perspective in which it is critical to determine how well people can be expected to live from the diagnosis onward [1]. Frequently, people who have survived cancer experience long-term and

Paula Martinez

paula.martinezl@campusviu.es

1 Department of Personality, Assessment and Psychological Treatments, Universitat de València, Valencia, Spain

2 Area of Health Sciences, Valencian International University, 46002 Valencia, Spain

3 Asociación Carena, Valencia, Spain

4 Medical Oncology Unit, Hospital Universitario Dr. Peset, Valencia, Spain

5 Medical Oncology Department, Instituto de Investigación Sanitaria INCLIVA, University of Valencia, Valencia, Spain late physical effects, such as pain, cognitive impairment, and fatigue $[2,3]$ in conjunction with psychological, social, and financial difficulties: fear of recurrence; trouble in reassuming family, work, and social roles, and issues surrounding employment [4]. Because of these challenges, cancer survivors are at high risk for distress or psychological morbidity [5]. Thus, achieving a better understanding of the consequences of cancer should be considered a priority in this interdisciplinary field.

Psychosocial distress in cancer designates a multi-determined unpleasant emotional experience of a psychological, social, spiritual, or physical nature that may interfere with the ability to cope effectively with cancer, its physical symptoms, and its treatment. Distress extends along a continuum, ranging from common normal feelings of vulnerability, sadness, and fears, to problems that can become disabling, such as depression, anxiety, panic, social isolation, and existential and spiritual crisis [6]. Distress has been called the sixth vital sign in cancer care [7]. Consequently, regular screening 
in the long-term follow-up care of people who have survived cancer has been recommended $[1,6]$.

Although there is a lack of robust data on the prevalence of clinical distress in post-treatment cancer survivorship, some researches point out that a substantial minority of survivors experience an increase in distress [8]. In addition, factors such as younger age, low socio-economic status and being unmarried are risk factors for psychological distress [9]. However, a recent systematic review concludes that there is no consistent evidence that demographic, clinical, or social variables are reliable risk factors for distress [10].

One of the largest cancer survivorship groups is colorectal cancer (CRC) survivors [11]. However, far few studies focus on this group and, consequently, relatively little is known about distress and associated risk factors in it [12, 13]. This limited information on CRC survival is accentuated by the fact that there are considerable inconsistencies in the timeframe and disease stage inclusion criteria of research involving CRC survivors [14]. Studies to date are scarce and show mixed data regarding the presence of distress and associated predictors. Research indicates a prevalence range of clinically significant distress from $7 \%$ at 12 months postdiagnosis to around $40 \%$ at five years post-diagnosis, and inconsistent associations with sociodemographic and medical variables $[15,16]$.

Supportive care encompasses a person-centered approach that aims to provide those affected by cancer with services necessary to meet their informational, emotional, social, and physical needs throughout the cancer trajectory [17]. Unmet supportive care needs are defined as concerns or needs that cancer survivors report as not being adequately addressed or met by the healthcare team [18]. Helping patients to address these needs requires knowing its frequency and nature, in order to enable healthcare systems to identify and implement appropriate services [19].

In the last decade, researchers have assessed the unmet needs and possible risk factors in adult cancer survivors, including those of CRC survivors [20-23]. However, due to limitations in the studies, it is difficult to compare and generalize the results obtained. It seems reasonable to think that cancer survivors' needs may differ according to the location of the cancer, the stage of disease control, and even the time elapsed since the end of treatment. In exploring unmet needs in cancer survivors, studies often group survivors with different cancer types and at different stages of the disease. In addition to the aforementioned limitations, inconsistency in the measurement, classification, and report of unmet needs is also to be found [24]. Consequently, a better understanding of unmet needs, including prevalence, type, and risk factors, is necessary to design programs to serve CRC cancer survivors better.

The cancer experience itself has distinct periods. These include the acute phase, encompassing the active treatment period, and the post-treatment phase. While we refer to the latter as the survivorship phase, we define a cancer survivor as a person who is living at a given point in time with a history of cancer [11]. The lack of correspondence between the terms survivor and survivorship represents a barrier to communication in both the clinical and research settings and hinders progress in understanding the post-treatment phase of the cancer care experience.

Considering the mentioned above, in this study, we focused on post-treatment CRC survivors and analyzed (i) the prevalence of distress, and unmet needs (assessed using a psychometrically validated instrument), and (ii) the potential sociodemographic and cancer-related risk factors for distress and unmet needs.

\section{Method}

\section{Procedure and participants}

A total of 235 colorectal cancer survivors were approached in several medical institutions and cancer patient associations in Spain. The study was approved by the Ethics Committee of the different participating medical institutions and cancer patient associations. Inclusion criteria were: minimum age of 18 years, colorectal cancer diagnosis, currently without any signs of recurrence, and primary treatment completed at least 1 month before participation in the study. Participants received information about the study, and 200 (85\%) gave informed consent and completed the questionnaire package. The mean age was 68 years $(\mathrm{SD}=10.53)$. Most participants were male (67\%), lived with a partner (73\%), had completed primary studies $(83 \%)$, and were retired or on sick leave (68\%). The most frequently received primary treatment strategy was surgery and chemotherapy (42\%). All of them had completed their primary treatment for cancer with an average of 53 months $(\mathrm{SD}=45.49)$ : $33 \%$ more than 5 years ago, $14 \%$ no more than 12 months ago, and 54\% had exceeded 12 months but had not yet reached 5 years (Table 1 ).

\section{Instruments}

\section{Emotional distress}

The Brief Symptom Inventory 18 (BSI-18) [25] is one of the most common checklists used in oncology context, not only to screen for psychological distress but also as a criterion measure to validate other measures of distress. It is comprising 18 items rated on a 5-point Likert scale and respondents are asked to rate each item in terms of how they have been feeling during the previous week. The 
Table 1 Sociodemographic and cancer-related characteristics of sample and association with distress $\left(N_{\text {Total }}=200 ; N_{\text {NonClinicalDistress }}=163\right.$; $N_{\text {ClinicalDistress }}=34$ )

\begin{tabular}{|c|c|c|c|c|}
\hline & $\begin{array}{l}\text { Total group } \\
N(\%)\end{array}$ & $\begin{array}{l}\text { Non-clinical distress } \\
N(\%)\end{array}$ & $\begin{array}{l}\text { Clinical distress }{ }^{\mathrm{a}} \\
N(\%)\end{array}$ & $p$ \\
\hline Age $(M=66.89 ; \mathrm{SD}=10.53 ;$ Range $=36-92)$ & & & & .141 \\
\hline$\leq 55$ & $24(12,4)$ & $17(10.6)$ & $7(20.6)$ & \\
\hline $56-65$ & $72(36.1)$ & $57(35.4)$ & $14(41.2)$ & \\
\hline$\geq 66$ & $102(51.5)$ & $87(54.0)$ & $13(38.2)$ & \\
\hline Sex & & & & .265 \\
\hline Female & $66(33.2)$ & $51(31.3)$ & $14(41.2)$ & \\
\hline Male & $133(66.8)$ & $112(68.7)$ & $20(58.8)$ & \\
\hline Living situation & & & & .353 \\
\hline Married/lived with partner & $144(73.1)$ & $120(74.5)$ & $22(66.7)$ & \\
\hline Single/divorced/widowed & $53(26.9)$ & $41(25.5)$ & $11(33.3)$ & \\
\hline Education level $(\mathrm{n}=)$ & & & & .486 \\
\hline Without studies & $32(17.0)$ & $24(15.6)$ & $7(21.9)$ & \\
\hline Primary studies & $70(37.2)$ & $59(38.3)$ & $11(34.4)$ & \\
\hline Secondary studies & $41(21.8)$ & $32(20.8)$ & $9(28.1)$ & \\
\hline Bachelor's degree & $45(23.9)$ & $39(25.3)$ & $5(15.6)$ & \\
\hline Employment status & & & & .022 \\
\hline Working outside home & $32(16.0)$ & $28(17.6)$ & $4(12.5)$ & \\
\hline Unemployed & $10(5.0)$ & $5(3.1)$ & $5(15.6)$ & \\
\hline Retired/on sick leave & $136(68.0)$ & $111(69.8)$ & $22(68.8)$ & \\
\hline Homemaker & $16(8.0)$ & $15(9.4)$ & $1(3.1)$ & \\
\hline Medical primary treatments & & & & .822 \\
\hline Surgery (S) & $67(33.5)$ & $55(33.7)$ & $11(32.4)$ & \\
\hline S + Chemotherapy (CT) & $84(42.0)$ & $68(41.7)$ & $14(41.2)$ & \\
\hline S + CT + Radiotherapy (RT) & $38(19.0)$ & $30(18.4)$ & $8(23.5)$ & \\
\hline Other ${ }^{b}$ & $11(5.5)$ & $10(6.2)$ & $1(2.9)$ & \\
\hline $\begin{array}{l}\text { Time elapsed since the end of primary treatment } \\
(M=53.08 ; \mathrm{SD}=45.49 ; \text { Range }=1-324)\end{array}$ & & & & .278 \\
\hline$\leq 12$ months (RE subgroup) & $27(13.5)$ & $25(15.3)$ & $2(5.9)$ & \\
\hline$>12$ months- $\geq 5$ years (ES subgroup) & $107(53.5)$ & $86(52.8)$ & $18(52.9)$ & \\
\hline$>5$ years (LTS subgroup) & $66(33.0)$ & $52(31.9)$ & $14(41.2)$ & \\
\hline
\end{tabular}

${ }^{a}$ Case criteria obtained based on $\mathrm{T}-\geq 63$ in GSI or at least in two subscales, using published norms for community sample

b "other" category groups together other primary treatment strategies that were infrequent in the study participants: chemotherapy, radiotherapy, surgery plus radiotherapy and chemotherapy plus radiotherapy

scale provides three symptom scores (anxiety, depression, and somatization) and an overall score that is a measure of psychological distress (Global Severity Index [GSI]) and offers complete and specific information by indicating not only an overall level of distress but also the symptoms that burden most to it. Scores were transformed into $\mathrm{T}$ scores to identify clinically significant distress using gender-specific normative data ( $T \geq 63$ on the GSI or at least on two subscales are classified as caseness). The Spanish version of the BSI-18 has shown adequate psychometric properties in previous studies of cancer populations [26]. In the present study, the GSI demonstrated satisfactory internal consistency (Cronbach's $\alpha=0.94$ ).

\section{Unmet supportive care needs}

The Cancer Survivors' Unmet Needs measure (CaSUN) assesses cancer-related needs experienced within the preceding month with 35 items that respondents rate as follows: not need/not applicable, met need, or unmet need as weak, moderate, or strong [27]. The Spanish version of CaSUN (CaSUN-S), which has shown satisfactory psychometric properties [28], supports the use of a hierarchical model composed of a total score and five domains: physical effects (4 items), psychological effects (11 items), comprehensive care and information (9 items), practical issues (6 items), and interpersonal relationships (5 items). For this study, responses were dichotomized in terms of met needs (not 
need/not applicable, met need, or weak unmet need) and unmet needs (moderate or strong unmet need).

\section{Statistical analyses}

Descriptive statistics were calculated to summarize sociodemographic, cancer-related, and psychosocial data. Chisquare tests were conducted to examine the association between caseness of distress, supportive unmet needs and sociodemographics (age, living situation, education level, and employment status), and cancer-related data (primary treatment and survival phase). The statistical significance level for analyses was $p \leq 0.05$. Statistical analysis was performed using IBM SPSS Statistics, version 22.0.

\section{Results}

\section{Prevalence, sociodemographic, and cancer-related predictors of distress}

The prevalence of distress among study survivors was $17 \%$. From the sociodemographic and cancer-related variables explored, employment status was the only one that showed a significant association with distress (Table 1).

\section{Prevalence, sociodemographic, and cancer-related predictors of unmet supportive care needs}

Only $14 \%$ of participants said they had no unmet needs, pertaining the most prevalent needs to the domain of comprehensive care and information (Table 2). If only the other domains of needs are considered, the percentage of survivors who indicated no unmet need increased from 19 to $46 \%$. Needs linked to practical issues and psychological effects were reported by one in three of the survivors, while needs associated with interpersonal relationships and physical effects were mentioned by one in four survivors.

Attending to the most prevalent specific needs, twothirds of the survivors reported needing that any complaints regarding their care were properly addressed. More than half said they needed to feel like they managed their health with the medical team, to know that doctors talk to each other to coordinate their care, and to have access to a local health care service available when they require it. In contrast, the least prevalent needs were those related to fertility and spiritual beliefs (Table 2).

The younger survivors (especially those $\leq 55$ years) reported a higher prevalence of needs in all domains except that of comprehensive care and information (Table 3). Unemployed participants pointed out more psychological, practical, and relational needs. Finally, survivors treated only with surgery indicated fewer needs related to the physical effects than the other subgroups.

\section{Association between distress and unmet supportive care needs}

The prevalence of the total needs, domains and specific needs, were positively associated with the presence of distress (Table 2). All supportive care needs (except 3 ) showed a higher prevalence in the distressed subgroup than in the non-distressed subgroup. Comprehensive care and information domain showed the lowest association with distress and the highest average prevalence in both subgroups. When this domain was excluded, the prevalence decreased considerably in the non-distressed subgroup (47\%), whereas in the stressed subgroup, the greater presence of needs related to other domains mitigated this decline $(85 \%)$.

\section{Discussion}

Approximately one in five CRC survivors showed clinically significant distress. This prevalence is midway between the values found by other authors in CRC survivors $[15,16]$. While previous findings are inconsistent regarding the association between distress and sociodemographic and medical variables $[12,15,16]$, our results showed a unique association between distress and employment status. Unemployed survivors were a risk subgroup for distress: representing 5\% of the participants, constituted $16 \%$ of the distressed survivors. Also, distress was associated with all needs domain, underscoring the importance of addressing CRC survivors' different unmet needs.

With an average of over 4 years of time elapsed since the end of the primary treatment, only $14 \%$ of participants said they had no unmet needs. As reflected in the literature [13, $19,20,22,29,30]$, the high presence of supportive care needs in CRC survivors was primarily associated with comprehensive care and information domain (with $82 \%$ of the survivors expressing at least one unmet need in this domain). The most prominent unmet needs from this domain were addressing of complaints, managing health with the medical team, effective communication between the medical staff, and access to local health care service. Comprehensive care and information needs were not related to any of the sociodemographic or cancer-related risk factors. Although these needs increased in prevalence in the distressed subgroup (94\%), they remained highly prevalent in the non-distressed subgroup (79\%). The importance of effective symptom management in CRC survival was highlighted by the presence of unmet physical effects needs ( $22 \%$ of prevalence). Besides, these needs were higher in those who received other treatments in addition to surgery. This association does suggest 
Table 2 Unmet supportive care needs: prevalence and association with distress $\left(N_{\text {Total }}=200\right.$;

$N_{\text {NonClinicalDistress }}=163$;

$N_{\text {ClinicalDistress }}=34$ )

\begin{tabular}{|c|c|c|c|c|}
\hline & $\begin{array}{l}\text { Total group } \\
N(\%)\end{array}$ & $\begin{array}{l}\text { Non-clinical distress } \\
N(\%)\end{array}$ & $\begin{array}{l}\text { Clinical distress }{ }^{\mathrm{a}} \\
N(\%)\end{array}$ & $p$ \\
\hline Comprehensive care information & $164(81.6)$ & $129(79.1)$ & $32(94.1)$ & .040 \\
\hline 1. Up to date information & $45(22.6)$ & $29(17.8)$ & $16(47.1)$ & .001 \\
\hline 2. Information for others & $45(22.6)$ & $32(19.6)$ & $13(38.2)$ & .019 \\
\hline 3. Understandable information & 79 (39.7) & $59(36.2)$ & $19(55.9)$ & .033 \\
\hline 4. Best medical care & $90(45.2)$ & $69(42.3)$ & $20(58.8)$ & .079 \\
\hline 5. Local health care service & $104(52.5)$ & $79(48.8)$ & $25(73.5)$ & .009 \\
\hline 6. Manage health with team & $116(58.3)$ & $91(55.8)$ & $25(73.5)$ & .056 \\
\hline 7. Doctor talk to each other & $115(57.8)$ & $87(53.4)$ & $28(82.4)$ & .002 \\
\hline 8. Complaints addressed & $134(67.3)$ & $107(65.6)$ & $27(79.4)$ & .117 \\
\hline 9. Complimentary therapy & $73(36.7)$ & $53(32.5)$ & $20(58.8)$ & .004 \\
\hline Physical effects & $45(22.4)$ & $26(16.0)$ & $17(50.0)$ & .001 \\
\hline 11. Manage side effects & $24(12.1)$ & $11(6.7)$ & $13(38.2)$ & .001 \\
\hline 12. Changes to quality of life & $26(13.1)$ & $13(8.0)$ & $13(38.2)$ & .001 \\
\hline 13. Fertility & $8(4.0)$ & $4(2.5)$ & $4(11.8)$ & .012 \\
\hline 26. Changes to my body & $20(10.0)$ & $7(4.3)$ & $13(38.2)$ & .001 \\
\hline Psychological effects & $69(34.3)$ & $41(25.2)$ & $26(76.5)$ & .001 \\
\hline 10. Reduce stress in my life & $30(15.1)$ & $13(8.0)$ & $17(50.0)$ & .001 \\
\hline 19. Concerns about cancer coming back & $39(19.5)$ & $22(13.5)$ & $17(50.0)$ & .001 \\
\hline 20. Emotional support for me & $31(15.5)$ & $13(8.0)$ & $18(52.9)$ & .001 \\
\hline 24. Talk to others & $29(14.5)$ & $19(11.7)$ & $10(29.4)$ & .008 \\
\hline 29. Move on with my life & $16(8.0)$ & $2(1.2)$ & $14(41.2)$ & .001 \\
\hline 30. Changes to beliefs & $21(10.5)$ & $8(4.9)$ & $13(38.2)$ & .001 \\
\hline 31. Acknowledging the impact & $15(7.5)$ & $5(3.1)$ & $10(29.4)$ & .001 \\
\hline 32. Survivor expectations & $14(7.0)$ & $6(3.7)$ & $8(23.5)$ & .001 \\
\hline 33. Decisions about my life & $20(10.0)$ & $8(4.9)$ & $12(35.3)$ & .001 \\
\hline 34. Spiritual beliefs & $9(4.5)$ & $3(1.9)$ & $6(17.6)$ & .001 \\
\hline 35. Make my life count & $16(8.0)$ & $4(2.5)$ & $12(35.3)$ & .001 \\
\hline Practical issues & $76(37.8)$ & $52(31.9)$ & $22(64.7)$ & .001 \\
\hline 14. Employment & $15(7.6)$ & $6(3.7)$ & $9(27.3)$ & .001 \\
\hline 15. Financial support & $43(21.7)$ & $25(15.4)$ & $18(52.9)$ & .001 \\
\hline 16. Life/travel insurance & $19(9.6)$ & $11(6.8)$ & $8(23.5)$ & .003 \\
\hline 17. Legal services & $22(11.1)$ & $11(6.8)$ & $11(32.4)$ & .001 \\
\hline 18. Accessible hospital parking & $24(12.1)$ & $15(9.3)$ & $9(26.5)$ & .005 \\
\hline 28. Ongoing case manager & $40(20.0)$ & $27(16.6)$ & $13(38.2)$ & .004 \\
\hline Relationships & $47(23.4)$ & $25(15.3)$ & $20(58.8)$ & .001 \\
\hline 21. Support partner/family & $27(13.5)$ & $10(6.1)$ & $17(50.0)$ & .001 \\
\hline 22. Impact on my relationship & $19(9.5)$ & $6(3.7)$ & $13(38.2)$ & .001 \\
\hline 23. New relationships & $12(6.0)$ & $2(1.2)$ & $10(29.4)$ & .001 \\
\hline 25. Handle social/work situations & $18(9.0)$ & $11(6.7)$ & $7(20.6)$ & .011 \\
\hline 27. Problems with sex life & $25(12.6)$ & $12(7.4)$ & $13(38.2)$ & .001 \\
\hline Total & $172(85.6)$ & $136(83.4)$ & 33 (97.1) & .039 \\
\hline
\end{tabular}

${ }^{\text {a }}$ Case criteria obtained based on $\mathrm{T}-\geq 63$ in GSI or at least in two subscales, using published norms for community sample that the inclusion of radiotherapy or chemotherapy in package increases treatment-related adverse effects and, with them, the likelihood of unmet needs in this domain. The fragmentation of health care - interactions with multiple health care providers - and less frequent contact with health care professionals decreased the level of support in the post-treatment period. In fact, receiving a longer aftercare period was a highly prevalent need among survivors in the study of Den Bakker et al. [20]. In addition, there is a substantial risk that surveillance for cancer recurrence 
Table 3 Sociodemographic and cancer-related predictors of unmet supportive care needs $(N=200)$

\begin{tabular}{|c|c|c|c|c|c|}
\hline & $\begin{array}{l}\text { Comprehensive care } \\
\text { information } \\
p \\
N(\%)\end{array}$ & $\begin{array}{l}\text { Physical effects } \\
p \\
N(\%)\end{array}$ & $\begin{array}{l}\text { Psychological } \\
\text { effects } \\
p \\
N(\%)\end{array}$ & $\begin{array}{l}\text { Practical issues } \\
p \\
N(\%)\end{array}$ & $\begin{array}{l}\text { Relationships } \\
p \\
N(\%)\end{array}$ \\
\hline Age & .663 & .001 & .024 & .001 & .003 \\
\hline$\leq 55$ & $21(87.5)$ & $12(50.0)$ & $14(58.3)$ & $16(66.7)$ & $11(45.8)$ \\
\hline $55-65$ & $57(79.2)$ & $20(27.8)$ & $23(31.9)$ & $30(41.7)$ & $19(26.4)$ \\
\hline$\geq 66$ & $83(81.4)$ & $11(10.8)$ & $30(29.4)$ & $28(27.5)$ & $15(14,7)$ \\
\hline Sex & .916 & .525 & .066 & .650 & .791 \\
\hline Female & $54(81.8)$ & $16(24.2)$ & $28(42.4)$ & $26(39.4)$ & $16(24.2)$ \\
\hline Male & $108(81.2)$ & $27(20.3)$ & $39(29.3)$ & $48(36.1)$ & $30(22.6)$ \\
\hline Living situation & .695 & .654 & .662 & .195 & .887 \\
\hline Married/lived with partner & $116(80.6)$ & $31(21.5)$ & $51(35.4)$ & $58(40.3)$ & $34(23.6)$ \\
\hline Single/divorced/widowed & $44(83.0)$ & $13(24.5)$ & $17(32.1)$ & $16(30.2)$ & $12(22.6)$ \\
\hline Education level $(\mathrm{n}=)$ & .194 & .287 & .799 & .130 & .943 \\
\hline Without studies & $28(87.5)$ & $3(9.4)$ & $12(37.5)$ & $11(34.4)$ & $8(25.0)$ \\
\hline Primary studies & $51(72.9)$ & $18(25.7)$ & $22(31.4)$ & $23(32.9)$ & $17(24.3)$ \\
\hline Secondary studies & $35(85.4)$ & $10(24.4)$ & $16(39.0)$ & $22(53.7)$ & $10(24.4)$ \\
\hline Bachelor's degree & $38(84.4)$ & $11(24.4)$ & $14(31.1)$ & $15(33.3)$ & $9(20.0)$ \\
\hline Employment status & .549 & .398 & .007 & .044 & .041 \\
\hline Working outside home & $26(81.3)$ & $6(18.8)$ & $10(31.3)$ & $11(34.4)$ & $6(18.8)$ \\
\hline Unemployed & $9(90.0)$ & $4(40.0)$ & $8(80.0)$ & $8(80.0)$ & $6(60.0)$ \\
\hline Retired/on sick leave & $111(81.6)$ & $31(22.8)$ & $41(30.1)$ & $48(35.3)$ & $30(22.1)$ \\
\hline Homemaker & $11(68.8)$ & $2(12.5)$ & $8(50.0)$ & $6(37.5)$ & $3(18.8)$ \\
\hline Medical primary treatments & .243 & .001 & .495 & .433 & .294 \\
\hline Surgery (S) & $57(85.1)$ & $7(10.4)$ & $19(28.4)$ & $21(31.3)$ & $14(20.9)$ \\
\hline S + Chemotherapy (CT) & $65(77.4)$ & $19(22.6)$ & $30(35.7)$ & $34(40.5)$ & $16(19.0)$ \\
\hline $\mathrm{S}+\mathrm{CT}+$ Radiotherapy $(\mathrm{RT})$ & $30(78.9)$ & $18(47.4)$ & $16(42.1)$ & $17(44.7)$ & $13(34.2)$ \\
\hline Other $^{\mathrm{a}}$ & $11(100.0)$ & $0(0.0)$ & $3(27.3)$ & $3(27.3)$ & $3(27.3)$ \\
\hline Time since primary treatment & .112 & .120 & .120 & .725 & .523 \\
\hline$\leq 12$ months (RE subgroup) & $25(92,6)$ & $10(37.0)$ & $11(40.7)$ & $12(44.4)$ & $7(25.9)$ \\
\hline$>12$ months- $\geq 5$ years (ES subgroup) & $82((76,6)$ & $22(20.6)$ & $41(38.3)$ & $39(36.4)$ & $27(25.2)$ \\
\hline$>5$ years (LTS subgroup) & $56(84.8)$ & $12(18.2)$ & $16(24.2)$ & $24(36.4)$ & $12(18.2)$ \\
\hline
\end{tabular}

a "other" category groups together other primary treatment strategies that were infrequent in the study participants: chemotherapy, radiotherapy, surgery plus radiotherapy and chemotherapy plus radiotherapy

may be prioritized above the management of chronic effects and provision of information and support to survivors [31], resulting in inadequate support and symptom management.

Among the psychological needs (34\% of prevalence), study participants highlighted the need for emotional support to manage the concern about cancer recurrence. Fear of recurrence has been reported as a major concern of cancer survivors and persists over an extensive post-diagnosis period, adversely affecting their quality of life and emotional well-being [22, 29]. Discussing symptoms and concerns with health providers offers reassurance about cancer recurrence and enables the transition to life beyond cancer [32, 33]. This possibility of effective communication with health care providers can be particularly relevant in the CRC, in which bowel dysfunction arising from its treatment is a constant reminder of potential recurrence, as symptoms resemble those experienced prior to diagnosis [34]. Thus, the solution is not merely a reduction of uncertainty, but it involves improving the survivor's understanding and management of the symptoms and bodily changes experienced [33]. Practical needs were reported by $38 \%$ of survivors, with the need for financial support and ongoing case manager being the most important. Although it is increasingly recognized that cancer can have a financial impact, relatively little is known about its prevalence or predisposing factors [35]. In settings like Spain, with a public healthcare system, responding to participants' demand for a continuous case manager could be a first step in the development of strategies to alleviate the economic impact of the CRC. 
At the interpersonal relationships domain (23\% of prevalence), the need for help to know how to support the partner/ family and to address problems with sex life were the most prominent. In fact, family members getting more support and guidance in the post-treatment period is a need frequently expressed by CRC survivors [20, 22]. In this regard, it should be remembered that cancer burdens not only the patients but also the partner/family to a comparable extent. Partners of patients with cancer are confronted with a variety of challenges and new, additional tasks regarding the disease, resulting in a decrease in mental health. These burdens are often overlooked, and psycho-oncological support or specific interventions for partners are rare [36]. Sexual complaints reported by CRC include physical concerns, emotional or motivational changes, relational challenges, and body image changes that can impact sexual relationships [14]. Although sexual dysfunction is one of the most common long-term effects of colorectal cancer treatment, this issue is rarely discussed among patients and their providers [31, 37]. Research findings suggest the importance of identifying and addressing sexual concerns and body image distress early in care in order to limit the negative effects on colorectal cancer patients' intimate relationships and wellbeing [38].

Previous studies indicate that younger age is linked to higher unmet needs [22, 29, 39]. In this regard, it has been argued that lower expectations about health services, greater stoicism, or greater taboo regarding psychological or sexual issues because of cohort attitudes may result in underreporting of needs in older survivors [39]. Even if the reasons for it are still unclear, what is evident is the need for additional attention to be paid to younger survivors. Finally, the highest distress and the greater presence of unmet needs in all domains among unemployed survivors (although the differences were not always significant) make this subgroup worthy of special attention. Although returning to work may be beneficial for many colorectal cancer survivors as it can help them to regain a sense of normalcy and routine [40], they can face greater risks of unemployment than the general population [41]. Future research should explore whether coordinated care interventions and other efforts that reduce financial or transportation burden can reduce disparities related to socioeconomic status in adjustment to cancer. In the meantime, greater recognition of cancer's financial impact on survivors and their families is necessary [35].

In short, we identified a high prevalence of unmet needs across multiple domains, particularly in the domain of comprehensive care and information in CRC survivors. These unmet needs persist years after treatment is complete. In addition, clinical distress, present in one in five survivors, was associated with a higher prevalence of unmet needs in all domains. Younger age and being unemployed were sociodemographic factors that identify those CRC survivors in most need of support. The diverse needs identified require a multi-professional and multi-agency approach to ensure that unmet needs are addressed or measures are offered [22]. The provision of specific budgetary and personnel resources to health care services presents itself as the optimal option to address psychosocial needs and manage the emotional distress reported by cancer survivors. However, the current economic and time constraints on service delivery and the continuing increase in the number of survivors make it difficult for health services to meet these needs [42], at least from an exclusively conventional care format. In this context, self-management programs may represent an effective strategy for bridging the gap between cancer survivors' needs and the ability of health services to meet them. Here, the survivor is expected to manage the physical and psychosocial consequences of cancer and its treatment, seeking support from the health care system when they feel it necessary, and making lifestyle changes where appropriate to improve health and well-being [43]. However, limitations in the designs and research make it advisable further research essential before recommending their integration into standard cancer care [44]. Given the increasing numbers of people with and beyond cancer, this research is of timely importance because a more personalized approach to follow-up care is needed $[8,43]$.

This study examined the prevalence, association, and possible sociodemographic and cancer-related risk factors of distress and supportive care needs in CRC, one of the least explored groups of cancer survivors, in spite of its high survival rate. We consider that another strength of the study was the use of a standardized instrument for the assessment of unmet care needs, which facilitates the comparison and progress of the research results. Nevertheless, several limitations should be noted. First, it is unclear whether the unemployment status was due to cancer. Although we addressed the distress profile and unmet needs of unemployed survivors as if this was the case, this issue was not adequately explored in our study. Second, the resulting small size in some of the subgroups established according to sociodemographic and cancer-related variables may have conditioned the finding of significant results. An additional limitation is the cross-sectional design used, which provides only correlational evidence. Further research with a larger sample size and incorporating longitudinal designs is needed to increase our knowledge about the survival phase in cancer, differentiating particular profiles that according to different sociodemographic and/or disease-associated variables allow early identification of those survivors at higher risk of impaired quality of life.

As future research is expected to shed more light on the key aspects of comprehensive care for the CRC survivor, our results suggest that communication channels should be opened in order to gain insight into the CRC assistance 
needs. Knowledge about survivor's fears, doubts, concerns, discomfort and perceived gaps in the health care enables the physician to provide support. The most prevalent need among study participants was comprehensive care/information. Thus, a change in the dynamics of physician-survivor communication that broadens the focus of attention to capture, in addition to the objective indicators of disease management, also those of a subjective nature can favorably affect both the quality of life and the survivor's self-management of his or her disease. The use of Patient Reported Outcome Measures (PROMS), such as CaSUN, can be useful for this purpose. These tools provide a structured range of issues to address, while encouraging dialogue about topics in which the survivor requires assistance, including those rarely discussed in routine health care. The improvement of the communication between health care professionals and survivors might also be facilitated with the implementation of Information and Communications Technologies (ICTs), in order to reach those patients with more difficulties to assist to in-person meetings, and also in order to avoid the overload of the sanitary system. Further research on this regard would be advisable. These recommendations for comprehensive person-centered care are of particular interest in the management of CRC survivors at higher risk, such as the unemployed and younger. Furthermore, this risk profile may be more present in the coming years by virtue of the economic crisis resulting from the current pandemic situation, as well as the increased incidence of CRC in individuals younger than 55 years of age [45].

Acknowledgements The authors are thankful to the participants and staff of collaborative centers for their cooperation: Hospital Universitario Dr. Peset de Valencia, Asociación CARENA Valencia, Hospital Clínico Universitario de Valencia, Asociación Europacolon, and AECC Valencia.

Author contribution All authors whose names appear on the submission made a substantial contribution to the conception or design of the work and/or the acquisition, analysis, or interpretation of data. Moreover, all authors have drafted the work and approved the version to be published.

Funding This work was supported by the Ministry of Economy and Competitiveness. Government of Spain [grant number PSI2013-45905-R].

Data and materials availability The datasets generated and analyzed during the current study are available from the corresponding author on reasonable request.

Code availability N/A

\section{Declarations}

Ethics approval and consent to participate This study was performed in accordance with the ethical standards as laid down in the 1964 Declaration of Helsinki and its later amendments. Approval was granted by the
Ethics Committee of the participating institutions. Informed consent was obtained from all individual participants included in the study.

Consent for publication N/A

Conflict of interest The authors declare no competing interests.

\section{References}

1. Albreht T, Kiasuwa R, Van den Bulcke M (2017) European guide on quality improvement in comprehensive cancer control. https:// cancercontrol.eu/archived/uploads/images/Guide/pdf/CanCon_ Guide_FINAL_Web.pdf. Accessed 26 Feb 2021

2. Miller KD, Nogueira L, Mariotto AB, Rowland JH, Yabroff KR, Alfano CM, Jemal A, Kramer JL, Siegel RL (2019) Cancer treatment and survivorship statistics, 2019. A Cancer Journal for Clinicians, CA. https://doi.org/10.3322/caac.21565

3. Wiltink LM, White K, King MT, Rutherford KC (2020) Systematic review of clinical practice guidelines for colorectal and anal cancer: the extent of recommendations for managing long-term symptoms and functional impairments. Support Care Cancer 28:2523-2532. https://doi.org/10.1007/s00520-020-05301-7

4. Duijts SFA, van Egmond MP, Spelten E, van Muijen P, Anema JR, van der Beek AJ (2014) Physical and psychosocial problems in cancer survivors beyond return to work: a systematic review. Psychooncology 23:481-492. https://doi.org/10.1002/pon.3467

5. National Comprehensive Cancer Network (2020a) NCCN Clinical Practice Guidelines in Oncology (NCCN Guidelines $\left.{ }^{\circledR}\right)$ : Distress management [v.2.2017]. https://www.nccn.org/professionals/physi cian_gls/pdf/distress.pdf. Accessed 26 Feb 2021

6. National Comprehensive Cancer Network (2020b) NCCN Clinical Practice Guidelines in Oncology (NCCN Guidelines $®$ ): Survivorship [v.2.2017]. https://www.nccn.org/professionals/physician_ gls/pdf/survivorship.pdf. Accessed 26 Feb 2021

7. Bultz BD, Carlson LE (2005) Emotional distress: the sixth vital sign in cancer care. J Clin Oncol 23:6440-6441. https://doi.org/ 10.1200/JCO.2005.02.3259

8. Niedzwiedz CL, Knifton L, Robb KA, Katikireddi SV, Smith DJ (2019) Depression and anxiety among people living with and beyond cancer: a growing clinical and research priority. BMC Cancer 19(1). https://doi.org/10.1186/s12885-019-6181-4

9. Williamson TJ, Stanton AL (2018) Adjustment to Life as a Cancer Survivor. Handbook of Cancer Survivorship 29-48.https://doi.org/ 10.1007/978-3-319-77432-9_3

10. Cook SA, Salmon P, Hayes G, Byrne A, Fisher PL (2018) Predictors of emotional distress a year or more after diagnosis of cancer: a systematic review of the literature. Psychooncology 27(3):791-801. https://doi.org/10.1002/pon.4601

11. Rowland JH, Mariotto AB, Elena JW (2018) Epidemiology. In M. Feuerstein, L. Nekhlyudov (Eds.) Handbook of Cancer Survivorship, 2nd edn, pp 7-28. https://doi.org/10.1007/ 978-3-319-77432-9_2

12. Han CJ, Gigic B, Schneider M, Kulu Y, Peoples AR, Ose J, Kölsch T, Jacobsen PB, Colditz Figueiredo JC, Grady WM, Li CI, Shibata D, Siegel EM, Toriola AT, Ulrich AB, Syrjala KL, Urich CM (2020) Risk factors for cancer-related distress in colorectal cancer survivors: one year post surgery. J Cancer Surviv. https://doi.org/ 10.1007/s11764-019-00845-y

13. Russell L, Gough K, Drosdowsky A, Schofield P, Aranda S, Butow PN, Westwood JA, Krishnasamy M, Young JM, Phipps-Nelson J, King D, Jefford M (2015) Psychological distress, quality of life, symptoms and unmet needs of colorectal cancer survivors near the 
end of treatment. J Cancer Surviv 9(3):462-470. https://doi.org/10. 1007/s11764-014-0422-y

14. Drury A, Payne S, Brady AM (2017) Cancer survivorship: advancing the concept in the context of colorectal cancer. Eur J Oncol Nurs 29:135-147

15. Dunn J, Ng SK, Holland J, Aitken J, Youl P, Baade PD, Chambers SK (2013) Trajectories of psychological distress after colorectal cancer. Psychooncology 22(8):1759-1765. https://doi.org/10.1002/pon. 3210

16. Lynch BM, Steginga SK, Hawkes AL, Pakenham KI, Dunn J (2008) Describing and predicting psychological distress after colorectal cancer. Cancer 112(6):1363-1370. https://doi.org/10.1002/cncr. 23300

17. Hui D (2014) Definition of supportive care. Curr Opin Oncol 26(4):372-379. https://doi.org/10.1097/cco.0000000000000086

18. Richardson A, Medina J, Brown V, Sitzia J (2007) Patients' needs assessment in cancer care: a review of assessment tools. Support Care Cancer 15(10):1125-1144. https://doi.org/10.1007/ s00520-006-0205-8

19. Li WWY, Lam WWT, Au AHY, Ye M, Law WL, Poon J, Kwong A, Suen D, Tsang J, Fielding R (2012) Interpreting differences in patterns of supportive care needs between patients with breast cancer and patients with colorectal cancer. Psychooncology 22(4):792-798. https://doi.org/10.1002/pon.3068

20. Den Bakker CM, Schaafsma FG, Huirne JAF, Consten ECJ, Stockmann HBAC, Rodenburg CJ, Klerk GJ, Bonger HJ, Anema JR (2018) Cancer survivors' needs during various treatment phases after multimodal treatment for colon cancer - is there a role for eHealth? BMC Cancer 18(1). https://doi.org/10.1186/s12885-018-5105-z

21. Fiszer C, Dolbeault S, Sultan S, Brédart A (2013) Prevalence, intensity, and predictors of the supportive care needs of women diagnosed with breast cancer: a systematic review. Psychooncology 23(4):361374. https://doi.org/10.1002/pon.3432

22. Kotronoulas G, Papadopoulou C, Burns-Cunningham K, Simpson M, Maguire R (2017) A systematic review of the supportive care needs of people living with and beyond cancer of the colon and/or rectum. Eur J Oncol Nurs 29:60-70. https://doi.org/10.1016/j.ejon. 2017.05.004

23. Maguire R, Kotronoulas G, Simpson M, Paterson C (2015) A systematic review of the supportive care needs of women living with and beyond cervical cancer. Gynecol Oncol 136(3):478-490

24. Martínez O, Andreu Y, Martínez P, Galdón MJ (2019) Emotional distress and unmet supportive care needs in survivors of breast cancer beyond the end of primary treatment. Support Care Cancer 27:1049-1057. https://doi.org/10.1007/s00520-018-4394-8

25. Derogatis LR (2013) Brief Symptom Inventory (BSI-18) Manual. NCS Pearson Inc, Minneapolis

26. Martínez P, Conchado A, Andreu Y, Galdón MJ (2019) Psychometric properties of the Brief Symptom Inventory-18 in a heterogeneous sample of adult cancer patients. Rev Latinoam Psicol 51:1-8. https:// doi.org/10.14349/rlp.2019.v51.n1.1

27. Hodgkinson K, Butow P, Hunt GE, Pendlebury S, Hobbs KM, Lo SK, Wain G (2007) The development and evaluation of a measure to assess cancer survivors' unmet supportive care needs: the CaSUN (Cancer Survivors' Unmet Needs measure). Psychooncology 16:796-804. https://doi.org/10.1002/pon.1137

28. Martínez P, Andreu Y, Conchado A (2021) Psychometric Properties of the Spanish Version of the Cancer Survivors' Unmet Needs (CaSUN-S) measure in breast cancer. Psicothema 33(1):155-163. https://doi.org/10.7334/psicothema2020.146

29. McMullen C, Bulkley J, Corley DA, Madrid S, Davis AQ, Hesselbrock R, Kurtilla F, Andreson CK, Arterburn D, Somkin CP, Pawloski PA, Chai NR, Feigelson HS (2019) Health care improvement and survivorship priorities of colorectal cancer survivors: findings from the PORTAL colorectal cancer cohort survey. Support Care Cancer. https://doi.org/10.1007/s00520-018-4299-6
30. Santin O, Murray L, Prue G, Gavin A, Gormley G, Donnelly M (2015) Self-reported psychosocial needs and health-related quality of life of colorectal cancer survivors. Eur J Oncol Nurs 19(4):336342. https://doi.org/10.1016/j.ejon.2015.01.009

31. Di Fabio F, Koller M, Nascimbeni R, Talarico C, Salerni B (2008) Long-term outcome after colorectal cancer resection patients' selfreported quality of life, sexual dysfunction and surgeons' awareness of patients' needs. Tumori J 94(1):30-35. https://doi.org/10.1177/ 030089160809400107

32. Clayton M, Dudley W (2009) Patient-centered communication during oncology follow-up visits for breast cancer survivors: content and temporal structure. Oncol Nurs Forum 36(2):E68-79. https:// doi.org/10.1188/09.onf.e68-e79

33. Taylor C, Cummings R, McGilly C (2012) Holistic needs assessment following colorectal cancer treatment. Gastrointest Nurs 10(9):42-49. https://doi.org/10.12968/gasn.2012.10.9.42

34. Custers JA, Gielissen MF, Janssen SH, de Wilt JH, Prins JB (2016) Fear of cancer recurrence in colorectal cancer survivors. Supportive Care Cancer 24:555-562. https://doi.org/10.1007/s00520-015-2808-4

35. Sharp L, O'Leary E, O'Ceilleachair A, Skally M, Hanly P (2018) Financial impact of colorectal cancer and its consequences. Dis Colon Rectum 61(1):27-35. https://doi.org/10.1097/dcr.0000000000000923

36. Bodschwinna D, Lorenz I, Bauereiss N, Gündel H, Baumeister H, Hoenig K (2020) PartnerCARE—a psycho-oncological online intervention for partners of patients with cancer: study protocol for a randomised controlled feasibility trial. BMJ Open e035599. https://doi. org/10.1136/bmjopen-2019-035599

37. Averyt JC, Nishimoto PW (2014) Psychosocial issues in colorectal cancer survivorship: the top ten questions patients may not be asking. J Gastrointest Oncol 5(5):395-400

38. Reese JB, Handorf E, Haythornthwaite JA (2018) Sexual quality of life, body image distress, and psychosocial outcomes in colorectal cancer: a longitudinal study. Support Care Cancer. https://doi.org/10. 1007/s00520-018-4204-3

39. Jorgensen ML, Young JM, Harrison JD, Solomon MJ (2012) Unmet supportive care needs in colorectal cancer: differences by age. Support Care Cancer 20(6):1275-1281. https://doi.org/10.1007/ s00520-011-1214-9

40. Stuhlfauth S, Melby L, Helles $\varnothing$ R (2017) Everyday life after colon cancer. Cancer Nurs 1. https://doi.org/10.1097/ncc.0000000000000506

41. Mehnert A (2011) Employment and work-related issues in cancer survivors. Crit Rev Oncol Hematol 77(2):109-130. https://doi.org/ 10.1016/j.critrevonc.2010.01.004

42. Alfano CM, Mayer DK, Bhatia S, Maher J, Scott JS, Nekhlyudov L, Merril JK, Hendreson TO (2019) Implementing personalized pathways for cancer follow-up care in the United States: Proceedings from an American Cancer Society-American Society of Clinical Oncology Summit. CA: A Cancer Journal for Clinicians 69:234-247

43. Grimmett C, Haviland J, Winter J, Calman L, Din A, Richardson A, Smith PW, Foster C (2017) Colorectal cancer patient's self-efficacy for managing illness-related problems in the first 2 years after diagnosis, results from the ColoREctal Well-being (CREW) study. J Cancer Surviv 11(5):634-642. https://doi.org/10.1007/s11764-017-0636-x

44. Boland L, Bennett K, Connolly D (2017) Self-management interventions for cancer survivors: a systematic review. Support Care Cancer. https://doi.org/10.1007/s00520-017-3999-7

45. Siegel, RL, Miller, KD, Jemal, A (2019). Cancer Statistics, 2018. CA: A Cancer Journal for Clinicians, 68(1), 7-30. https://doi.org/10.3322/ caac. 21442

Publisher's note Springer Nature remains neutral with regard to jurisdictional claims in published maps and institutional affiliations. 